\title{
TRABALHO NO SÉCULO XXI: FLEXIBILIDADE E REDUÇÃO DE DIREITOS. ENTREVISTA COM JACOB CARLOS LIMA.
}

\author{
WORK IN THE XXISt CENTURY: \\ FLEXIBILITY AND REDUCTION OF RIGHTS. \\ INTERVIEW WITH JACOB CARLOS LIMA. \\ TRAVAIL AU XXIème SIĖCLE: \\ FLEXIBILITÉ ET RÉDUCTION DES DROITS. \\ ENTRETIEN AVEC JACOB CARLOS LIMA. \\ TRABAJO EN EL SIGLO XXI: \\ FLEXIBILIDAD Y REDUCCIÓN DE DERECHOS. \\ ENTREVISTA CON JACOB CARLOS LIMA.
}

José Ricardo Ramalho* Laura Senna Ferreira**

\section{Quais as principais mudanças no mundo do trabalho nesse início de século XXI?}

Jacob Carlos Lima: Este início de século ainda paga as contas do século anterior, com uma retomada do discurso neoliberal voltado a flexibilização das relações de trabalho. Sem dúvida contraditório, mas um aspecto novo e não sei da sua temporalidade efetiva, está no protecionismo norte-americano na contramão do discurso da liberação dos mercados. A guerra comercial em curso promovida pelo governo norte americano com a China, ilustra essa novidade.

Para o trabalho, acredito que se mantém a tendência da precarização do trabalho a partir da flexibilização dos contratos, o aumento da prestação de serviços, formalizados ou não, e a utilização cres-

\footnotetext{
* Doutor em Ciência Política; Professor Titular do Departamento de Sociologia e do Programa de Pós-Graduação em Sociologia e Antropologia da Universidade Federal do Rio de Janeiro (UFRJ), Rio de Janeiro, RJ, Brasil; E-mail: josericardoramalho@gmail.com

** Doutora em Sociologia; Professora Adjunta do Departamento de Ciências Sociais e do Programa de Pós-Graduação em Ciências Sociais da Unversidade Federal de Santa Maria (UFSM), Santa Maria, RS, Brasil; E-mail: laurasennafe@hotmail.com
} 
cente de plataformas digitais. Em outros termos, o capital prossegue em sua busca pela redução de custos e aumento da lucratividade, eliminando barreiras e fronteiras à sua expansão. Mas os trabalhadores não estão passivos frente a essa desorganização do mundo do trabalho. Diversas formas de resistências, organizadas ou não, marcam esses processos.

\section{Trabalho flexível e redução de direitos: de que modo isto afeta o mundo do trabalho hoje?}

Jacob Carlos Lima: Afeta de forma determinante, pois as novas formas organizacionais e tecnologias, tem a flexibilidade como parâmetro. Flexibilidade na produção, nas jornadas de trabalho e de formas de contratação. A relação tempo espaço nesse novo momento do capitalismo coloca em questão a própria noção do tempo necessário para realização de tarefas e/ou produção de mercadorias. Discute-se como mensurar o valor-trabalho dentro desse novo contexto. Direitos sociais vinculados ao trabalho são percebidos como custos para o capital, pelos aumentos dos salários e das obrigações sociais, das taxas pagas tendo como referência a folha de pagamento. Considera-se o debate fordista do trabalhador com sua reprodução social garantida e que teria como retorno a maior produtividade, como ultrapassado. O Estado, vai abandonando sua função de mediador das relações capital-trabalho, se colocando abertamente como gestor do capital. É o que temos acompanhado nas últimas décadas.

\section{Qual a relevância das novas tecnologias nos processos produtivos e em novas atividades de trabalho?}

Jacob Carlos Lima: As novas tecnologias têm afetado toda a nossa vida. Por um lado, facilita o trabalho, eliminando tarefas e racionalizando atividades. Por outra, elimina ocupações e saberes consolidados. Podemos falar em tendências, mas ainda não existe um consenso sobre isso. Tem interpretações que consideram que o futuro é a precarização total das relações de trabalho, com a predo- 
minância de plataformas digitais e a automação/robotização crescente da produção. Desemprego em massa e a informalidade imperaria - contratos zero hora (se existirem) e ausência total de controle sobre a exploração do trabalho. Eu não sou tão pessimista. Existe uma tendência a um aumento da precarização, sem dúvida, mas a sociedade não é estanque. Existem reações, existem movimentos, ora difusos, ora organizados, que estabelecem limites. Os conflitos de classe assumem outras configurações, mas não desaparecem, e as tecnologias em si são positivas, melhora as nossas condições de vida e trabalho, desde que todos tenham acesso a seus benefícios.

\section{Qual a relevância do debate sobre precariedade e precarização do trabalho nos dias de hoje?}

Jacob Carlos Lima: Temos que distinguir a precariedade presente no trabalho subordinado, e a precarização como um processo de perda de condições de trabalho e direitos anteriormente existentes. O debate é muito centrado no desmonte, ou fragilização, das políticas de bem-estar social dos países capitalistas avançados, a partir das conquistas obtidas após a $2^{\mathrm{a}}$ guerra mundial. Foram os chamados 25 anos gloriosos. Nos anos 1970, teve início seu desmanche. Os trabalhadores começaram a ter seus direitos sociais questionados, restringidos ou mesmo eliminados. Também podemos falar das novas gerações, nesses mesmos países, altamente escolarizadas e sem perspectivas de um emprego seguro como seus pais. Para nós, no capitalismo periférico, estamos perdendo a perspectiva dos direitos crescentes que assistimos desde os anos 1930 e que passou a ser combatido mais fortemente na década de 1990. Digo perspectiva, pois a maioria dos trabalhadores no Brasil, por exemplo, nunca teve acesso a esses direitos. As reformas e reestruturações a partir dos 90 atingiram diretamente trabalhadores formais que perderam seus empregos e foram precarizados. Houve uma precarização em determinadas carreiras e atividades que tiveram seus direitos sociais restringidos e contratos de trabalho precarizados. Por outro lado, tivemos o surgimento de atividades, vinculados a novas tecnologias e novos 
setores produtivos em que o contexto de seu surgimento deu-se dentro do que chamamos de capitalismo flexível. Aí temos uma precarização estrutural da sociedade na qual estão as relações de trabalho, mas não de uma atividade que nem existia antes e que, portanto, não foi precarizada. É precária desde sua origem. E aí voltamos ao início, o trabalho subordinado é precário, por excelência. Mas esse debate deve ser matizado, pois se observarmos grupos de profissionais e de trabalhadores, do serviço público e do privado, temos situações que ora se aproximam, ora se afastam radicalmente desses processos. E isso vincula-se não apenas ao aspecto econômico, mas político, das relações de força entre as classes e frações de classe, as estratégias de dominação e outros fatores que devem ser considerados. Um exemplo, as carreiras jurídicas no Estado brasileiro, altos salários e benefícios, longe de qualquer precariedade, cheia de privilégios e poder político para mantê-los.

\section{Como se coloca hoje a questão da informalidade?}

Jacob Carlos Lima: Entendendo a informalidade, como ausência de qualquer tipo de contrato ou vínculo de trabalho legalmente estabelecido, ela se constitui tradicionalmente na nossa conhecida "viração". Um tempo atrás, Fernando Henrique Cardoso em sua fúria modernizante neoliberal afirmou que no Brasil não havia desemprego e que isso era problema de país rico. E ele tinha razão, porque aqui ninguém fica esperando o seguro desemprego entre um contrato e outro. Grande parte nunca teve contrato algum, e sempre teve que se virar. Quando não, morria de fome. Lembrar que sempre estivemos presentes nos mapas da fome no mundo, apenas com um intervalo desta última década em que as coisas pareciam que iam melhorar de vez. O discurso neoliberal, em sua reflexão do capitalismo como a saída para todos os males e para o paraíso terrestre, mesmo que apenas para uma minoria empreendedora, positivou a informalidade. O que era sinônimo de atraso de países periféricos, virou trabalho flexível por excelência, uma prova do caráter empreendedor dos trabalhadores da vasta periferia deste mundo. Mas 
parece que esse discurso não convenceu essa periferia que ainda sonha imigrar e ter acesso as benesses do capitalismo de bem-estar que ainda restou na Europa, Estados Unidos e Japão. A atual crise migratória ilustra esse fenômeno. Mas a informalidade chegou por lá também. Desde os anos 1980, tornou-se um problema do capitalismo global - não é que não existisse, mas era percebida como algo que seria resolvido com o desenvolvimento econômico. E agora, essa nova informalidade, o novo aqui utilizado como recurso explicativo das mudanças recentes do capitalismo - está virando gig economy, chique, mas tão precária quanto a outra. Entra o capitalismo digital, de plataforma, ao lado do vendedor de bugigangas, do prestador de serviços pessoais e eventuais, da sweat-shop, da oficina no fundo da casa, uma infinidade de trabalhadores, precários e/ou precarizados. As mercadorias produzidas globalmente atravessam fronteiras, mudam de status, ora formais, ora informais, contrabandos diversos, ilegais, ilícitas, assim como seus trabalhadores, empreendedores de si próprios para sobreviverem.

\section{De que modo o apelo ao empreendedorismo interfere nas ques- tões do emprego e da geração de renda?}

Jacob Carlos Lima: Os informais seriam empreendedores conforme o economista peruano Hernando de Soto, em texto do final dos anos 1980. O problema dos pobres na América Latina não seria a ausência do Estado, mas o excesso. É o discurso que se propaga dessa década para frente, junto com as novas teorias organizacionais que buscam agora um trabalhador que seja empreendedor de si mesmo, que faça a diferença na empresa. Inovação e empreendedorismo tornam-se a panaceia do novo espírito do capitalismo. O trabalho flexível pressupõe um trabalhador ativo e não acomodado que não permaneça muito tempo numa empresa, que esteja se atualizando de forma permanente. As novas tecnologias exigem um trabalhador “criativo", flexível e móvel. O assalariamento, por sua vez é visto como acomodação, a fala de não dar o peixe, mas ensinar a pescar. O SEBRAE torna-se o grande divulgador da lógica empreendedora 
com treinamentos e formação no tema. Políticas públicas acompanham a onda frente a redução da oferta de empregos formais e do aumento da informalidade. Formalizar o trabalhador informal, não é assegurar um emprego com direitos, situação fora das perspectivas do capitalismo flexível, mas que invista em sua empregabilidade e sobrevivência, ao mesmo tempo em que passa a ter acesso ao mercado financeiro, pode pagar sua previdência pública ou privada. $\mathrm{O}$ MEI é resultado disso. Não é negativo por definição, é uma forma de regular de controlar um mercado sem controle pelo Estado, formalizando formas diversas do se virar para gerar renda. Em si não gera renda, apenas organiza o já existente e incentiva as atividades por conta própria, diminuindo a pressão por empregos regulares.

\section{Como vê a recente reforma trabalhista no Brasil?}

Jacob Carlos Lima: Essa reforma veio completar o serviço que ficou inacabado pelas políticas neoliberais da década de 1990. A América Latina tem uma tradição de ser mais realista que o rei. Fez o serviço recomendado pelas instituições financeiras multilaterais que nem os países centrais fizeram. A Argentina não quebrou por acaso nos anos 2000. No Brasil, em 2002, o governo foi derrotado nas urnas, mas a lógica econômica permaneceu, embora com uma maior presença do Estado na economia e a implementação de políticas sociais, que significou, por sua vez, grandes avanços sociais. O impeachment de 2016, e o golpe que significou, recolocou o país na situação anterior, com a volta ao poder dos grupos políticos e econômicos que sempre controlaram o Estado brasileiro. E sem votos. Aliás, a imprensa tem destacado os discursos empresariais e de seus porta-vozes economistas, nos quais as eleições preocupam o mercado e que sem as reformas não existiriam investimentos. Em outros termos, o voto atrapalha e a democracia não é algo necessário. Um mistério esse ente chamado mercado. Os dados apresentados para justificar essa reforma, assim como a da previdência, são sempre formulas abstratas, nada de dados positivos que provem alguma coisa. E parece que isso se estende ao Direito, para o qual na ausência 
de provas, prevalece a convicção. Está evidente desde o início, que a reforma trabalhista veio atender aos anseios empresariais e que a função do governo é atendê-los. A lógica é a redução dos custos do trabalho em nome de uma modernização que significa dar aos patrões todo o poder para usufruir a mão de obra sem óbices jurídicos. Veja-se a legalização dos contratos temporários, do trabalho intermitente, da redução da fiscalização do trabalho, dos limites a justiça do trabalho e mesmo tentativas de sua eliminação, entre outras estratégias para fragilizar o trabalho organizado. Mas ainda tem muita agua para passar pelo moinho e também tem resistências, interpretações jurídicas destoantes, o que leva, para desgosto dos seus formuladores, para o campo da luta política, mesmo que inicialmente desfavorável para os trabalhadores, não significa que irá permanecer assim.

\section{Existe uma saída coletiva para enfrentar o desmonte da proteção trabalhista e a precarização dos laços de emprego? Como ficam os sindicatos neste contexto, ou outras formas de manifestação coletiva?}

Jacob Carlos Lima: Falamos muito sobre transformações no mundo do trabalho e nos detemos pouco na questão sindical. Essas transformações levaram a uma fragilização do sindicalismo e uma necessidade de atualização frente aos novos desafios colocados pela crescente desregulamentação das relações capital-trabalho e para entender o funcionamento das novas ocupações e vínculos flexíveis no mercado. Algumas categorias mantém alguma força organizativa em determinados espaços, como os metalúrgicos vinculados principalmente a montadoras, mas temos que considerar os efeitos dos processos de reespacialização da produção que tem deslocado ou aberto unidades em pequenas cidades sem tradição de trabalho industrial e sem qualquer resquício de trabalho organizado. Mais, as redes de terceirização industrial também têm deslocado fábricas para outros espaços onde a ausência de opções de emprego e/ ou ocupação dificulta a organização. Num outro espectro, as ocupações vinculadas as tecnologias digitais mesmo quando fortemente 
formalizadas, enfrentam o problema da desespacialização virtual das unidades (um trabalhador no interior de São Paulo pode prestar serviços para uma empresa em Nova York, por exemplo), dos home offices que oferecem um trabalho "virtual" sem um território físico ou, quando existente, fragmentado. Mas mesmo nesses setores temos grandes unidades que concentram trabalhadores, sem contar os Call Centers que são as novas fábricas, locais com grande concentração de trabalhadores. Essa concentração, em tese, favorece a organização e resistência dos trabalhadores, mas o discurso e atuação sindical deve estar sintonizado com uma população jovem e escolarizada que é um diferencial em relação a situações anteriores, o que exige uma atualização do discurso e das práticas sindicais. Por outro lado, as tecnologias digitais, ao mesmo tempo que favorecem o controle empresarial, permite a conexão virtual entre os trabalhadores levando a formas quase espontâneas de organização, greves e protestos como tem acontecido em empresas como Uber, Amazon e outras que funcionam nessas plataformas. Ou seja, as manifestações coletivas permanecem e se reconfiguram, vale agora os sindicatos se preparar para fazerem o mesmo. Essa reconfiguração precisa se adaptar às mudanças da força de trabalho, do maior nível de informação, e por consequência também, mais susceptível as formas de manipulação político e ideológica presente nas redes sociais e na mídia. É um desafio e tanto, mas é uma possibilidade de conquistar a adesão de trabalhadores para além do sindicalismo assistencial, dos espetáculos artísticos no primeiro de maio com sorteio de automóveis, ou ainda de um discurso vinculado a um passado industrial que nem sempre diz muita coisa às novas gerações de trabalhadores. Insisto na importância das redes sociais digitais na organização dos trabalhadores pois pode estabelecer caminhos de novas formas de representatividade. 